\title{
From ancient times to modern: realizing the power of data visualization in healthcare and medicine
}

\author{
Mohamed Elgendi ${ }^{1,2,3,4^{*}}$, Newton Howard ${ }^{4}$, Amir Hussain ${ }^{5}$, Carlo Menon ${ }^{3}$ and Rabab Ward ${ }^{1}$
}

*Correspondence:
moe.elgendi@gmail.com
'School of Electrical and Computer
Engineering, University of British
Columbia, V6T 1Z4, Vancouver,
Canada
2Faculty of Medicine, University of
British Columbia, V1Y 1T3,
Vancouver, Canada
Full list of author information is
available at the end of the article

\begin{abstract}
Data visuals (scientific images) display and express various amounts and types of information, and, as the saying goes,"an image is worth 1,000 words." Based on a review of two studies, a new estimation of how many words an image is actually worth was calculated in an attempt to quantify the complicated biological process of image perception. The result revealed that an image is actually worth more than 30,000 words. This new value estimation provides insight into the power of images. Given that figures, graphs, and data visualizations are types of images commonly used in research and publications, every produced figure is important and must be carefully considered during the publication process.
\end{abstract}

Keywords: Visual communication, Information graphics, Descriptive figures, Visual perception, Knowledge translation

\section{Introduction}

With a quick look at history and now, we can see that images have played an important role in transferring ideas since the beginning of humanity. It is rare to find a long-standing civilization, such as the ancient Egyptian civilization, that did not visualize their progress and contributions. For example, the ancient Egyptians drew their medical instruments in a very organized style on their walls, as you can see in Fig. 1. Even though there is no color in Fig. 1, the visualization transferred the message to the audience in a simple and effective manner. By looking at Fig. 1, we can extract a lot of information, such as that the medical knowledge in ancient Egypt was evolved and that they had advanced knowledge of human anatomy. Also, the small tools show that they had a general idea of the location in the body of the inner organs and how to do small incisions. There is no doubt that visualizing the medical tools was enough to show medical advancement and that the knowledge was passed on to the practitioners of medicine over the years. 


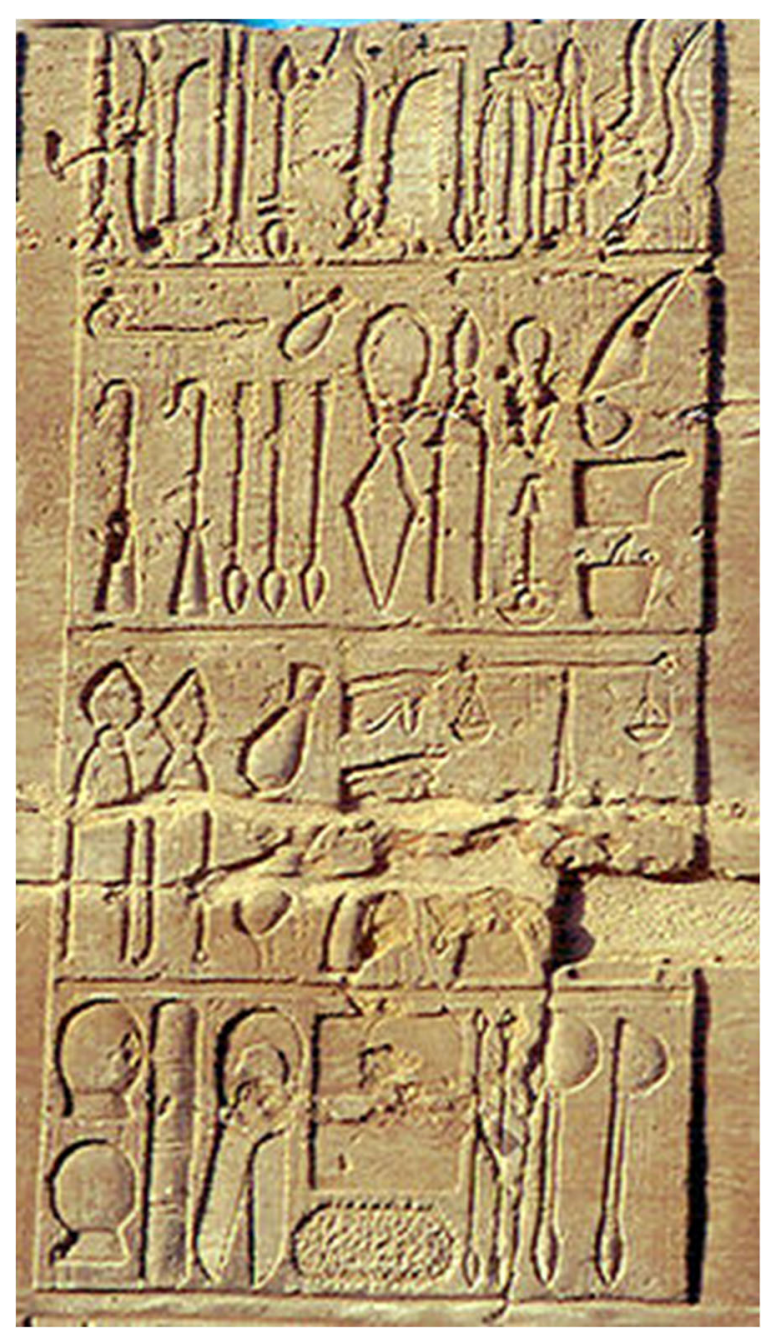

Fig. 1 Ancient Egyptian medical instruments depicted in a Ptolemaic period inscription on the Temple of Kom Ombo

From each medical instrument in Fig. 1, we might think of how many diseases they were able to diagnose and what types of surgeries they were able to conduct. We could write many words on each instrument based on this data visual; the question is, how many words could we write? This is the main question behind this article. We will try to answer this question in the next sections. However, before answering this question, we will discuss the recent literature confirming the importance of an image.

\section{Recent research confirming image impact}

In 2009, Dansereau and Simpson [1] suggested that images that include node-link graphic representations can enhance communication among clinical research, counseling, supervision and training, and organizational functioning. However, they did not quantify what an image was worth in terms of words; rather, they were confirming the importance of an image for knowledge translation. In 2012, Wechsler [2] mentioned the importance of images for Endovascular therapy. He confirmed that it is logical that understanding the physiology and anatomy through imaging modalities will improve endovascular therapy 
and reduce morbidity. However, he did not quantify what an image is worth in terms of words; rather, he was confirming the importance of an image for Endovascular therapy. In 2013, Lorena et al. [3] hypothesized that images showing rooms owned by individuals with hoarding disorder would cause the owners to be judged as having a higher amount of possessions, being less tidy, being less functional, having a higher number of different classes of items hoarded, and being less clean than the owners of rooms in pictures showing healthy collectors. Their results showed that it is useful for the clinician to ask for images to help in diagnosing hoarding disorder when a home visit is not feasible. However, they did not quantify what the images were worth in terms of words; rather, they were confirming the importance of an image for tackling depression and anxiety. In 2016, McLoughlin and Ripley [4] questioned the usefulness of a Nomogram as a data visual to determine the probability of a clinical event occurring in a given patient. However, they did not quantify what the data visual was worth in terms of words; rather, they were trying to show the lack of validation of the Nomogram.

In 2016, Hales et al. [5] investigated the power of images for weight loss. They found that the use of images to self-monitor dietary intake and receive feedback has the potential to reduce user burden for self-monitoring. However, they did not quantify what the data visual was worth in terms of words; rather, they were trying to show the impact of images for weight loss.

\section{Quantification methodology}

The common saying "Use a picture. It's worth a thousand words," which first appeared in a 1911 newspaper article [6], is often used without much thought regarding its meaning or origin. A similar phrase, "One Look Is Worth A Thousand Words," appeared in a 1913 newspaper article [7]. Now the main questions here are why was this specific number (one thousand) used? and is there any scientific basis for this claim? Scientists are trained to question any given value and the certainty of such a value, which is what prompted this investigation. In 1977, Blackwell [8] asked the same question: How many words is a picture worth? He designed a primitive scientific experiment asking participants to describe in words the same information expressed in a single diagram by others. The results of his experiment, based on the average number of words used by all participants, were that a picture is worth 84.1 words. However, the images provided to the participants were simple black and white diagrams.

In 2020, we will try to address and answer the questions raised by providing a rough estimation (a more realistic estimation of this number) based on two recent studies: an invasive study and a non-invasive study. In the first study [9], a guinea pig retina was attached to an array of electrodes while images were flashed. Based on the generated response from the eye, they estimated that an image transfers information to the human retina at a rate of 8.75 megabits per second $(\mathrm{Mb} / \mathrm{s}$ ) (we can say that the speed of processing an image is $10 \mathrm{Mb} / \mathrm{s})$. The second, non-invasive study [10] found that the rate at which the brain receives and processes an image is $1.5 \mathrm{Mb} / \mathrm{s}$. Now we need to know the speed of reading words, here is a study [11] showed that the reading rate can be as fast as 300 words per minute (wpm). If we assume that each word is processed at a speed of 10 bits per second in our brain-based on the study published by Dijksterhuis and Nordgren [12], then the speed of reading a word is $50 \mathrm{~b} / \mathrm{s}([300 \mathrm{wpm}] \mathrm{x}[10 \mathrm{~b}] / 60)$. Note that the quantification process provided in this paper is based on the English language, and the language 


\section{1}

One Look Is Worth A Thousand Words--

One look at our line of Republic, Firestone, Miller and United States tires can tell you more than a hundred personal letters or advertisements.

WE WILL PROVE THEIR VALUE BEFORE YOU INVEST ONE DOLLAR IN THEM.

Ever consider baying Supplies from a catalog?

What's the uso ! Call and see what you are buying. One look at our display of auto. mobile and motorcycie accessories will conTHAT WE HAVE EVERYTHING FOR THE AUTO

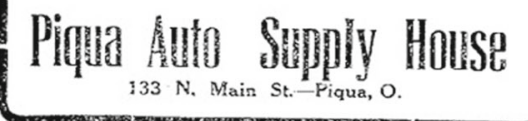

Fig. 2 How much is an image really worth?
2020

\section{One Look is} Worth More than 10 Thousand Words

of choice may slightly change the assumption and calculation [13]. We can calculate an estimation for how many words an image is worth based on each of the studies. In the first study, one image is worth (i.e. equivalent to processing) 200,000 words (calculation is based on $[10 \mathrm{Mb} / \mathrm{s}] /[50 \mathrm{~b} / \mathrm{s}])$, and in the second study, one image (200 x 300 pixels) is worth 30,000 words (calculation is based on $[1.5 \mathrm{Mb} / \mathrm{s}] /[50 \mathrm{~b} / \mathrm{s}]$ ). Based on these calculations, we can conclude that one image is worth at least 30,000 words and up to 200,000 words. Figure 2 reflects a change in the understanding of how many words an image is worth.

\section{Relevance of quantification}

The resulting estimation derived from these calculations is a simplified value that attempts to quantify the complicated biological process of image perception, and it provides some insight into the power of images used to convey information. For example, brain images are believed to have a particularly persuasive influence on the public perception of research on cognition [14]. Considering that we can now estimate that an image is worth over 30,000 words, the importance of this finding can be illustrated by using the analogy of a thesis. Often, the word count for a dissertation for PhD students in the Faculty of Education at the University of Melbourne needs to be 30,000 words or more [15]. Thus, when producing an image that summarizes a concept or idea, it can be as powerful and impactful as a written thesis. Morrison and Vogel [16] reported the equal impact of different data visuals (pie charts, boxplots, and info graphics) or images for persuading audiences. This is interesting because in the scientific realm, charts are considered images; however, scientists often produce images without always paying attention to their quality and impact [17]. Considering that these images are intended to clearly convey specific concepts and results, scientists must appreciate the real value of a produced image and focus their efforts into creating effective, impactful, and intentional images. With the proper application of data visualization techniques, scientists can elevate their work 
and the impact of their results if an image is created thoughtfully (see: https://youtu.be/ 19N6RBzZXJk for basic concepts for data visualization).

\section{An example of an impactful data visual}

For our point view, Fig. 3 is the most interesting data visual in health care published in 2016. It shows the differences between different countries in terms of life expectancy (years) and health expenditure (US dollars) per citizen on average. We can write an essay based on this data visual. In fact, the effort behind collecting data from different countries, normalization, and data processing itself can take thousands of words. It is clear from Fig. 3 that the US is spending more money on health care and achieving the lowest life expectancy compared to other countries.

One of the interesting things about the figure is the mapping of three dimensions into two dimensions. Here we have three variables, supposed to be presented with three axes: health expenditure, life expectancy, and time. The data analyst was skillful in norma-

Life expectancy vs. health expenditure over time (1970-2014) OurWorlc Health spending measures the consumption of health care goods and services, including personal health in Data care (curative care, rehabilitative care, long-term care, ancillary services and medical goods) and collective services (prevention and public health services as well as health administration), but excluding spending on investments. Shown is total health expenditure (financed by public and private sources).

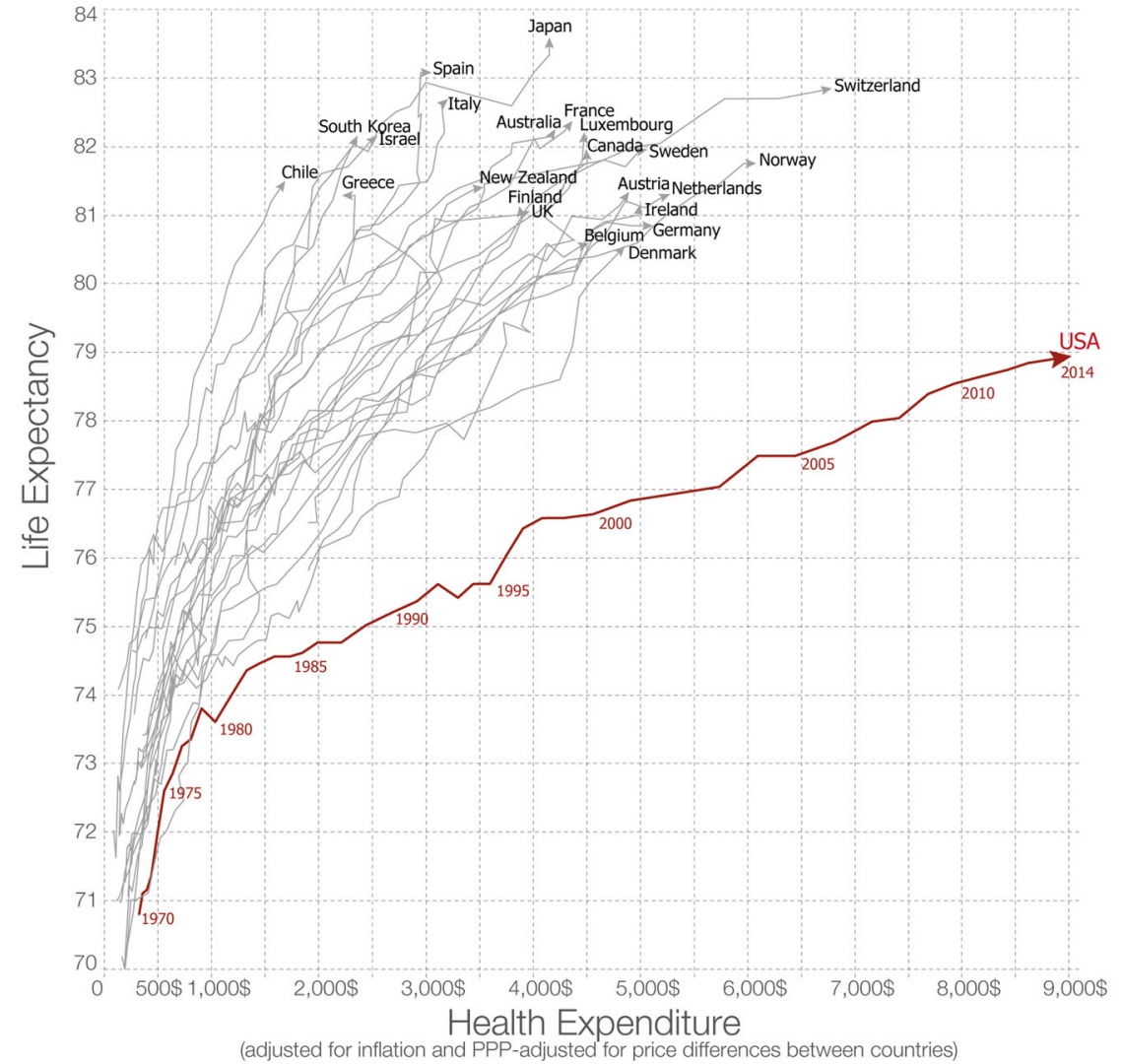

Data source: Health expenditure from the OECD; Life expectancy from the World Bank Licensed under CC-BY-SA by the author Max Rose The interactive data visualization is available at OurWorldinData org. There you find the raw data and more visualizations on this topic.

Fig. 3 An example of effective Data Visual. The data visual is represented in 2-dimensional reflecting three dimensional features (health expenditure, life expectancy, and years). It clearly shows the wastefulness of USA healthcare system compared to other countries over the same number of years 
lizing every line by the period of 1970-2014, providing impactful information and showing progress over time.

\section{Recommendations}

Following the previous example, there is a need to establish guidelines for data visualization regarding what to do and what not to do. We believe that we need to evolve the publication system, and we have two recommendations: 1) create a position for a new role in our organizations and call it "data visualist," and 2) create a competition for best data visuals for knowledge translation. The role of the data visualist should be to check the main figures of a publication to ensure that the figures are truly "scientific," "knowledge translatable," and "intuitive." The competition should give feedback to scientists, especially those in health care, on how to provide robust yet efficient images that are attractive and informative.

\section{Can we use images all the time?}

The answer is no. Overusing images and not producing proper images is just adding noise. Redundant information is not useful; sometimes adding an image to text can add no value to the text. A prime example was published in 2015. Holland et al. [18] demonstrated that the addition of images within undergraduate histology exam multiple choice questions had no overall influence on item difficulty or measures of item discrimination. They concluded that the use of images in this context is statistically not useful and suggested that their inclusion within items should be based upon the principles of constructive alignment.

\section{Conclusion}

An image is worth over 30,000 words and, if crafted properly, can significantly improve the quality of disseminated research results. Appreciating the power of an image elevates the level of impact a publication will have and can create a medium that enables researchers from different disciplines to easily understand cross and interdisciplinary results and conclusions. With this kind of knowledge sharing with easy-to-understand visuals by scientists with different backgrounds, the overall research community will reap the benefits of increased results sharing, as well as new interactions and improved communication among different research communities. Moreover, an effective image can be understood by others outside the research community who may benefit from the information being shared. A well-done data visual can bring experts and nonexperts together and can be understood and verbalized by scientists with different backgrounds.

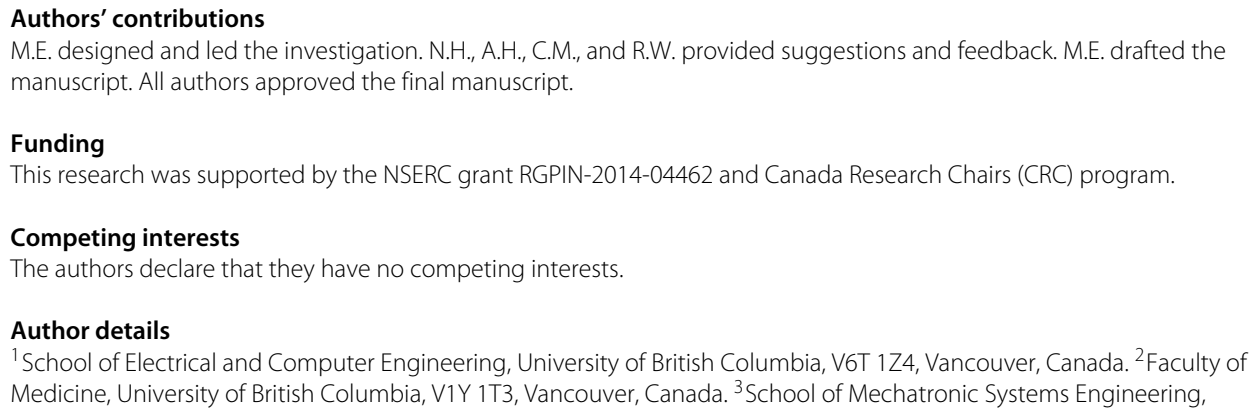


Simon Fraser University, V5A 156, Burnaby, Canada. ${ }^{4}$ Nuffield Department of Surgical Sciences, University of Oxford, OX3 9DU, Oxford, UK. ${ }^{5}$ Data Science and Cyber Analytics Research Group, Edinburgh Napier University, EH11 4DY, Edinburgh, UK.

Published online: 22 July 2020

\section{References}

1. Dansereau DF, Simpson DD. A picture is worth a thousand words: The case for graphic representations. Prof Psychol Res Pract. 2009:40(1):104.

2. Wechsler LR. Endovascular therapy and imaging: Is a picture worth a thousand words? Neurology. 2012;79(13 Supplement 1):77-8.

3. de la Cruz LF, Nordsletten AE, Billotti D, Mataix-Cols D. Photograph-aided assessment of clutter in hoarding disorder: is a picture worth a thousand words?. Depression Anxiety. 2013;30(1):61-6.

4. McLoughlin KC, Ripley RT. Clinical nomograms: Is a picture worth a thousand words? J Thorac Cardiovasc Surg. 2017;153(2):470

5. Hales S, Dunn C, Wilcox S, Turner-McGrievy GM. Is a picture worth a thousand words? few evidence-based features of dietary interventions included in photo diet tracking mobile apps for weight loss. J Diabetes Sci Technol. 2016;10(6):1399-405.

6. Advice, Speakers Give Sound. Syracuse Post Standard. 1911:18

7. One Look Is Worth A Thousand Words. Piqua Leader-Dispatch. 1913. p. 2.

8. Blackwell AF. Correction: A picture is worth 84.1 words. In: Proceedings of the First ESP Student Workshop; 1997. p. 15-22. https://www.cl.cam.ac.uk/ afb21/publications/Student-ESP.html.

9. Koch K, McLean J, Segev R, Freed MA, Berry II MJ, Balasubramanian V, Sterling P. How much the eye tells the brain. Curr Biol. 2006;16(14):1428-34.

10. Potter MC, Wyble B, Hagmann CE, McCourt ES. Detecting meaning in rsvp at 13 ms per picture. Atten Percept Psychophys. 2014;76(2):270-9.

11. Tan A, Nicholson T. Flashcards revisited: Training poor readers to read words faster improves their comprehension of text. J Educ Psychol. 1997;89(2):276.

12. Dijksterhuis A, Nordgren LF. A theory of unconscious thought. Perspect Psychol Sci. 2006;1 (2):95-109.

13. Broadbent DE. Perception and Communication. Oxford: Pergamon; 1958

14. McCabe DP, Castel AD. Seeing is believing: The effect of brain images on judgments of scientific reasoning Cognition. 2008;107(1):343-52.

15. Larcombe W, McCosker A, O'Loughlin K. Supporting education phd and ded students to become confident academic writers: An evaluation of thesis writers' circles. J Univ Teach Learn Pract. 2007;4:54-63.

16. Morrison J, Vogel D. The impacts of presentation visuals on persuasion. Inf Manag. 1998;33(3):125-35

17. Elgendi M. Scientists need data visualization training. Nat Biotechnol. 2017;35(10):990-1.

18. Holland J, O'Sullivan R, Arnett R. Is a picture worth a thousand words: an analysis of the difficulty and discrimination parameters of illustrated vs. text-alone vignettes in histology multiple choice questions. BMC Med Educ. 2015;15(1): 184

\section{Publisher's Note}

Springer Nature remains neutral with regard to jurisdictional claims in published maps and institutional affiliations.

Ready to submit your research? Choose BMC and benefit from:
- fast, convenient online submission
- thorough peer review by experienced researchers in your field
- rapid publication on acceptance
- support for research data, including large and complex data types
- gold Open Access which fosters wider collaboration and increased citations
- maximum visibility for your research: over 100M website views per year
At BMC, research is always in progress.
Learn more biomedcentral.com/submissions

